
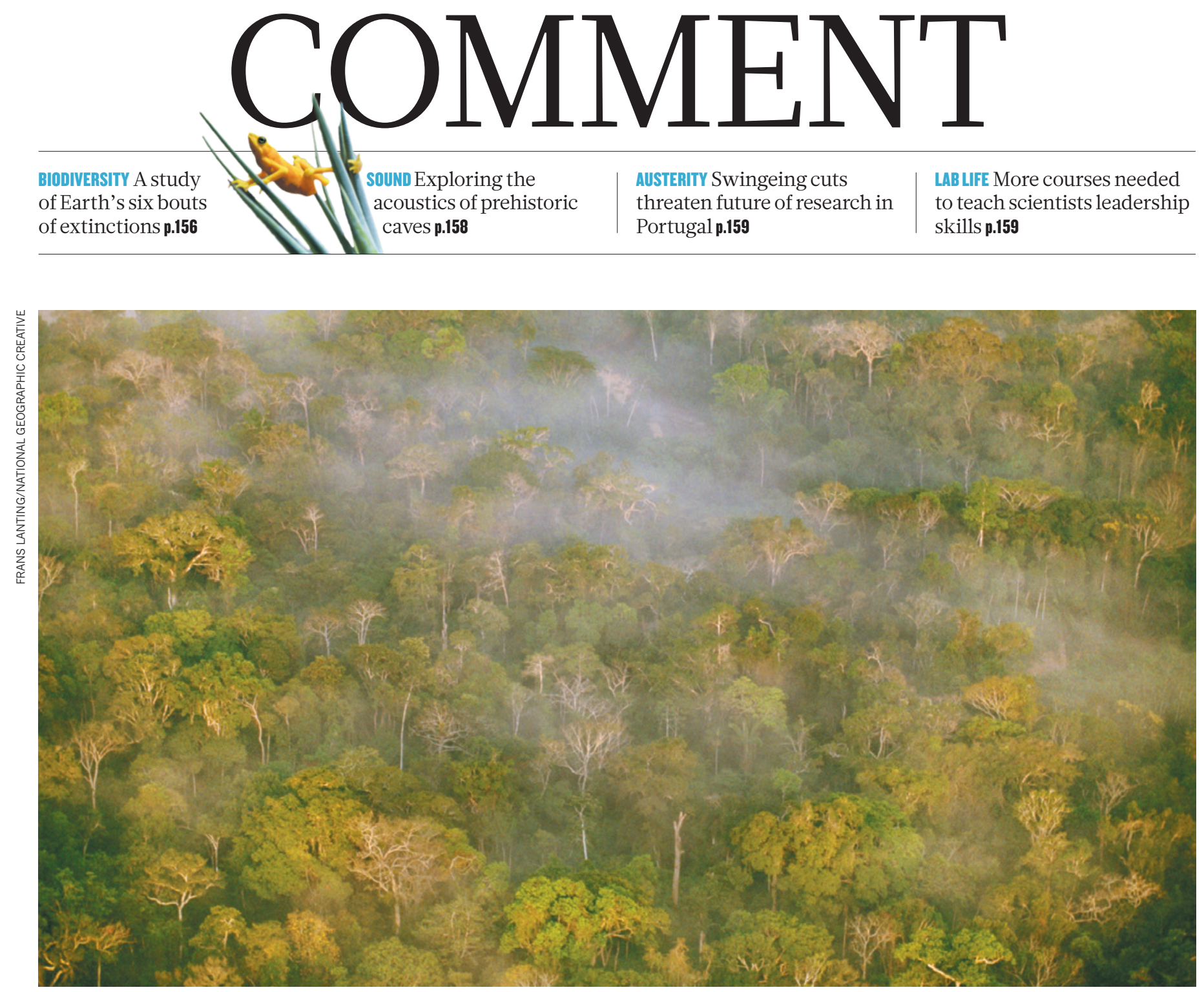

Lowland rainforest in Manu National Park, Peru.

\title{
Managing forests in uncertain times
}

\section{Increasing both forest stocks and timber harvest will buy time while we learn more about how trees absorb carbon, say Valentin Bellassen and Sebastiaan Luyssaert.}

\section{$\mathrm{T}$}

The best way to manage forests to store carbon and to mitigate climate change is hotly debated. Trees absorb carbon dioxide from the atmosphere, and wood can be a substitute for fossil fuels and carbon-intensive materials such as concrete and steel. In the past few decades, the world's forests have absorbed as much as 30\% (2 petagrams of carbon per year; $\mathrm{PgC}_{\mathrm{C}} \mathrm{ar}^{-1}$ ) of annual global anthropogenic $\mathrm{CO}_{2}$ emissions ${ }^{1}$
- about the same amount as the oceans. Two-thirds of forests are managed.

Much has been learned about the carbon cycle in forests, but there are still too many gaps in our knowledge. New observations have called long-accepted theories into question: the finding that unharvested forests, for example, are absorbing more carbon than they release ${ }^{2}$, accounting for half the sink, is contrary to the tenet of ecology, known as Odum's framework, that carbon flows in natural forests should be in equilibrium.

This carbon-sink behaviour of mature forests is attributed to large-scale environmental changes that violate the assumption of the steady conditions underlying Odum's framework: higher atmospheric $\mathrm{CO}_{2}$ concentrations are accelerating tree growth worldwide and nitrogen emitted by industry, agriculture and fossil-fuel burning is 


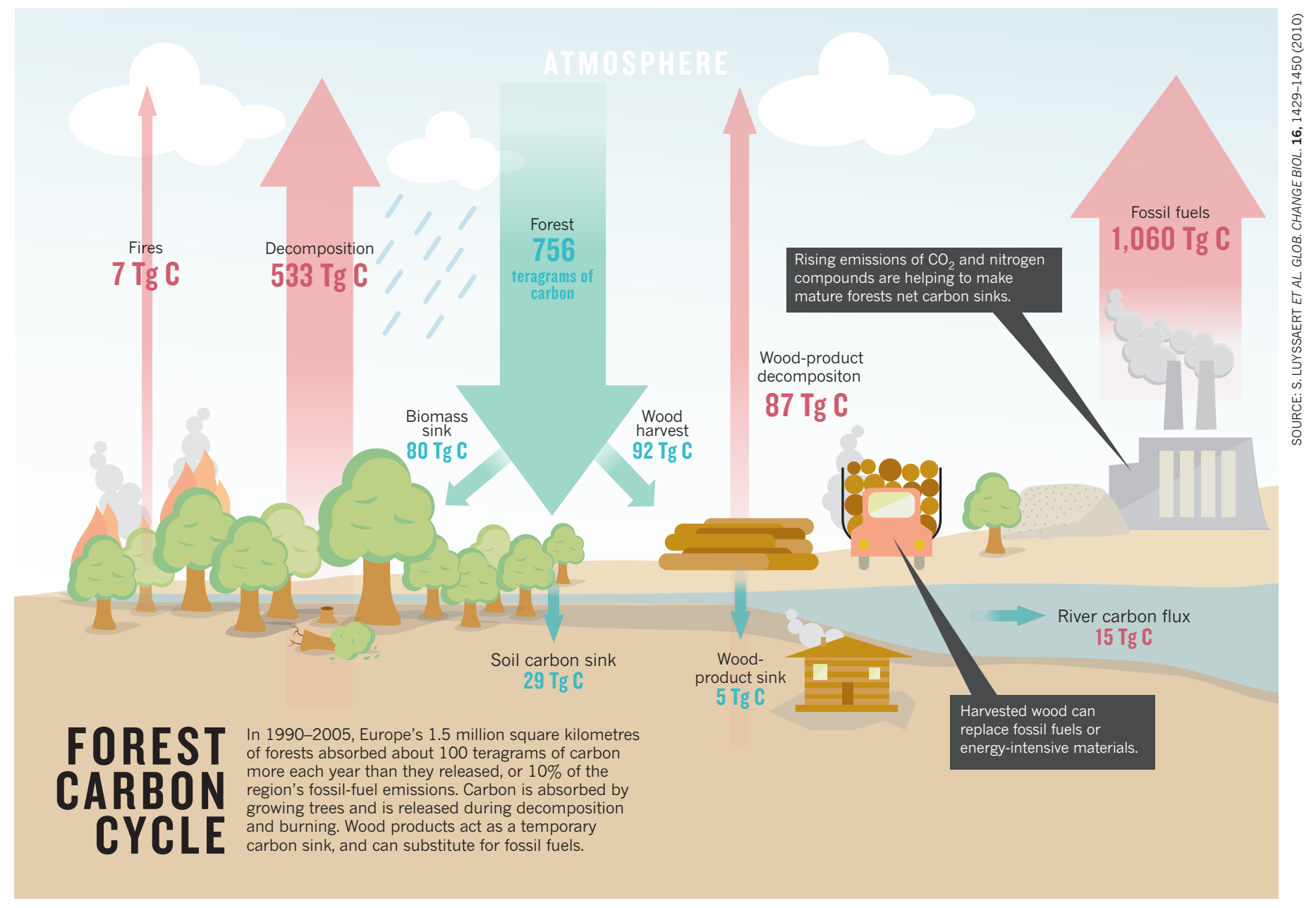

$\checkmark$ increasingly fertilizing managed forest soils in Europe, China and the eastern United States ${ }^{3}$.

To make good decisions about how to cultivate forests for climate-change mitigation, such as whether it is better to harvest or conserve trees, we must better understand the cause and future behaviour of this in situ carbon sink. Until more is known, we propose that forestry management should prioritize 'win-win' strategies - those that increase both forest stocks and timber harvest, through measures such as protecting trees from animals, or replacing dying or lowproductivity forests (see 'Forest carbon cycle').

\section{GLOBAL DRIVERS}

So far, most discussions about the impact of climate change on forests have focused on the rising rate of locally devastating events such as forest fires, infestations, droughts and storms. The past decade saw 410 million cubic metres of wood felled in four major storms in Europe, a decade's worth of Amazonian carbon sequestration lost in severe droughts in 2005 and 2010, a record heat wave with forest fires affecting 23,000 square kilometres in Russia in 2010, and the bark beetle pandemic that has affected 130,000 square kilometres and killed 435 million cubic metres of trees in British Columbia, Canada, since 2004.

Regionally, these events have had large socio-economic and ecological impacts. The windstorms that hit Europe in 1999, for example, destroyed one-third of the region's annual carbon sequestration ${ }^{4}$ by forests, and halved the price of timber in France and other affected countries. But such events are insignificant over decades and at the global scale. The

"Today's
forest
management
is more of a
gamble than
a scientific
debate."
Pacific El Niño and La Niña climate oscillations - primarily the tropical forest and peatland fires associated with them - are the only regional disturbances evident in globally averaged atmospheric $\mathrm{CO}_{2}$ records ${ }^{5}$.

At the same time, atmospheric records and forest inventories show that forests have been taking up ever more $\mathrm{CO}_{2}$ in the past 50 years $^{1}$. Experimental and modelling studies have established that currently, the global forest sink is driven mainly by changes in atmospheric $\mathrm{CO}_{2}$ concentration and in nitrogen deposition. The competing explanation, that today's rapid tree growth is a recovery from ancient climate or harvesting losses, seems unlikely because it requires that regions around the globe, such as the Amazon and the Congo Basin, were simultaneously affected. Such a coincidence should have left traces of soot and enhanced $\mathrm{CO}_{2}$ concentrations in air bubbles in glacial ice core samples, and these are not seen.

The size of the global forest carbon sink has increased alongside rising $\mathrm{CO}_{2}$ levels (see 'Global land sink'). Industrial and agricultural activities and fossil-fuel burning emit nitrogen compounds that fertilize forests up to hundreds of kilometres away ${ }^{3}$. The rate of carbon storage in temperate forests in Europe and North America is well correlated with their exposure to this nitrogen deposition. Other changing climate factors, such as temperature and rainfall, and changing forest-management strategies, such as leaving trees to grow for longer before cutting them back, seem to be of secondary importance to the global carbon budget of forests, although they may be locally important ${ }^{6,7}$.

A quantified understanding of how all these drivers shape the forest carbon sink is lacking. And predictions of how they will change during this century remain uncertain. Projections that $\mathrm{CO}_{2}$ might overtake nitrogen deposition as the dominant cause of the sink in temperate zones, as 
$\rightarrow$ industrial emissions fall, are controversial. Physiological constraints, such as trees living shorter lives as their growth accelerates and soil fertility falling in mature woodlands, are often missing from models, as is the effect of temperature on tree growth.

As a result, the picture is confused. Different models disagree on whether the forest carbon balance in 2100 will be positive or negative, let alone its magnitude. Even where models make the same assumptions, such as no change in current emissions and no forest management, they have wildly different predictions. Models assuming that rising temperatures and $\mathrm{CO}_{2}$ concentrations will increase photosynthesis, which absorbs

$\mathrm{CO}_{2}$ faster than respiration emits $\mathrm{CO}_{2}$, suggest that the biosphere could absorb up to $10 \mathrm{PgCyear}^{-1}$. This is five times today's terrestrial carbon sink and matches current $\mathrm{CO}_{2}$ emissions from fossil-fuel burning and deforestation. If respiration dominates, others predict that the biosphere will become a carbon source of $6 \mathrm{PgCyear}^{-1}$ (ref. 8), doubling the current $\mathrm{CO}_{2}$ emissions and thus requiring emissions reductions far beyond what is being discussed.

\section{THREE WAYS OUT}

The future trajectory of the carbon sink influences how forests should be managed for climate-change mitigation. If the world's forests remain net absorbers, conservation would be appealing. Preserved mature forests would absorb almost as much carbon as younger ones. Because decomposing harvest residues and roots add immediately to the $\mathrm{CO}_{2}$ emissions, and it takes decades for increased use of wood products to compensate, avoiding harvest could generate extra climate benefits, at least in the short run.

Conversely, if mature forests become carbon sources, increased harvesting may be the best mitigation option. Harvesting would reduce losses from decomposition while promoting wood as a fossil-fuel substitute.

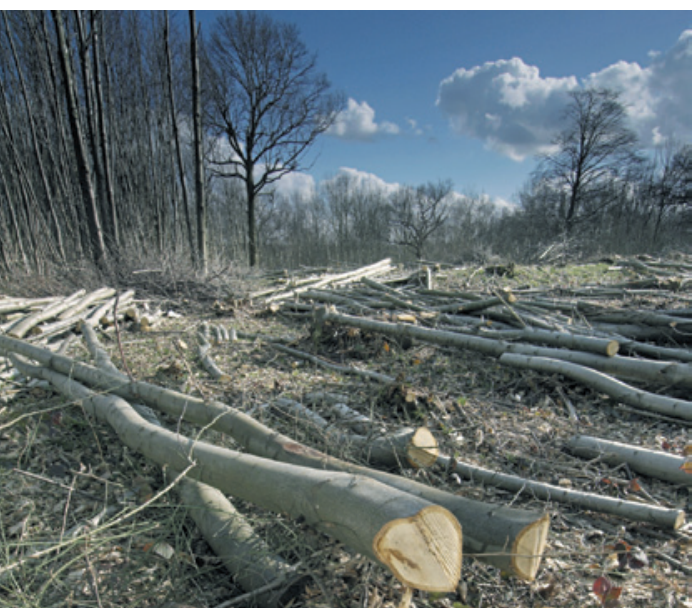

Harvesting reduces carbon emissions from decomposition.

\section{GLOBAL LAND SINK}

The quantity of carbon absorbed by trees and other types of vegetation per hectare of land has risen in the past 50 years as anthropogenic carbon dioxide and nitrogen emissions have grown. This is despite the world's forest area falling by around $2 \%$ since 1990

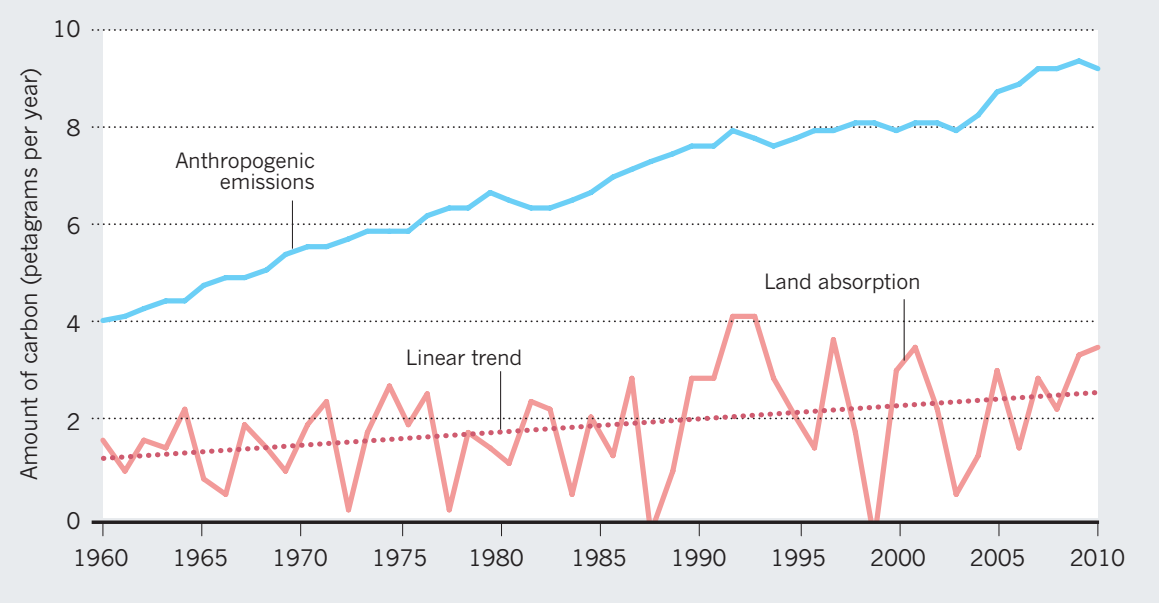

While a scientifically robust prediction of the persistence of the forest carbon sink is worked out, three safe strategies should be followed.

First, so that studies can be compared and uncertainties addressed, scientists should state their assumptions more clearly. The Earth system modelling community should define and report a set of internationally agreed performance quality criteria, based on an ability to reproduce trends in large data sets that include interactions relevant to understanding the effects of nitrogen and $\mathrm{CO}_{2}$ on the forest sink. To provide these data sets, large-scale remote sensing needs to be combined with frequent monitoring of local test sites, such as the permanent plots of national forest inventories, with monitoring networks such as Fluxnet (which coordinates measurements of $\mathrm{CO}_{2}$ exchanges), and with controlled experiments, such as $\mathrm{CO}_{2}$-enrichment studies.

The forest-science community should make explicit the assumed behaviour of unmanaged forests that lies behind its assessment of forest mitigation strategies and its life-cycle analysis for wood products. Most of these studies ${ }^{9}$ assume that unmanaged forests are carbon neutral, which overestimates the climate benefits of harvest. Oth$\mathrm{ers}^{10}$ assume that the in situ forest sink will be sustained forever, underestimating the climate benefits of harvest.

Second, the most carbon-efficient uses of wood should be encouraged. Harvesting more timber could be, especially if the forest sink starts shrinking, a good climate-change mitigation strategy, but to be effective it must be targeted to uses that will save the most tonnes of $\mathrm{CO}_{2}$ per cubic metre harvested. In construction, for example, wood can substitute for steel or cement for studs or walls, and can then be recovered, recycled and burnt.
Third, forest-management techniques that increase both the amount of wood produced and the carbon stock retained in the forest should be prioritized. When not in conflict with other forest uses, replacing dying or low-productivity stands, protecting young sprouts from damage after harvest, planting tree mixes that are more resilient, and optimizing fertilizer use and tree growth by adding nitrogen-fixing species in afforestation projects, will contribute to climatechange mitigation no matter how the global carbon sink evolves.

Today's forest management is more of a gamble than a scientific debate. By following 'no-regret' strategies, we can buy time while we learn more. The future of the world's forest should not depend on tossing a coin.

Valentin Bellassen is at the Centre for Economics and Sociology in Rural Areas (CESAER), National Institute for Agronomic Research (INRA), Dijon, France. Sebastiaan Luyssaert is at the Laboratory for Climate Sciences and the Environment (LSCE), Atomic and Alternative Energy Commission (CEA), Gif-sur-Yvette, France. e-mail:valentin.bellassen@dijon.inra.fr

1. Pan, Y. et al. Science 333, 988-993 (2011).

2. Luyssaert, S. et al. Nature 455, 213-215 (2008).

3. Solberg, S. et al. For. Ecol. Mgmt 258, 1735-1750 (2009).

4. Lindroth, A. et al. Glob. Change Biol. 15, 346-355 (2009).

5. Reichstein, M. et al. Nature 500, 287-295 (2013).

6. Bellassen, V. et al. Glob. Change Biol. 17, 3274-3292 (2011)

7. Desai, A. R., Moorcroft, P. R., Bolstad, P. V. \& Davis, K. J. J. Geophys. Res. 112, G01017 (2007).

8. Friedlingstein, P. et al. J. Clim. 19, 3337-3353 (2006).

9. Lippke, B. et al. Carbon Mgmt 2, 303-333 (2011).

10. Hudiburg, T. W., Law, B. E., Wirth, C. \& Luyssaert, S. Nature Clim. Change 1, 419-423 (2011). 